\title{
The Challenges and Policy Choices Faced by Aging of Population in Xinjiang Production and Construction Corps*
}

\author{
Shasha Chen \\ Southwest Minzu University \\ Chengdu, China
}

\author{
Xingyu Qi \\ Southwest Minzu University \\ Chengdu, China
}

\begin{abstract}
The Xinjiang Production and Construction Corps (Corps for short) is the largest special organization in China that is in charge of defending the border field and the military enterprise that is owned by the Communist Party. However, the current aging level in Corps exceeds the global average, which has become the area with most serious aging problem in China and has brought enormous challenges to economic development and society. Through the analysis of the challenges faced by economic development, industrial development, labor force, social security system and pension service system in Corps, it is proposed to improve the old-age security system and improve the medical security system, to use policies to adjust the structure and establish and improve the incentive mechanism to attract and retain young talents to balance the composition of the labor force, and to make full use of the human resources of the elderly to actively build the "productive aging" of the Corps, vigorously develop the old age cause of the Corps, and speed up the construction of the pension service system in Corps and other measures to deal with population aging to realize the rapid economic development in Corps.
\end{abstract}

Keywords-Xinjiang Production and Construction Corps; aging; challenges; policy choice

\section{INTRODUCTION}

According to international standards, when the number of elderly people aged 60 or 65 in the society exceeds $10 \%$ and $7 \%$ of the total population, the society has entered an aging society. The data of Corps have already far exceeded this standard. As early as 1982, there were 265,200 elderly people over 60 years old, accounting for $12 \%$ of the total population Corps Under such background, the Corps faces more and more serious social and economic development problems and the aging problem needs to be solved urgently. This paper takes Aging problem in Corps as the research content and probes into the active countermeasures against

*Scientific research project: This article is a research result of key project of master of Graduate Innovative Research Project in Southwest University for Nationalities in 2018 "Challenges and Policy Choice faced by Aging of Population of Xinjiang Production and Construction Corps" (Project No. CX2018SZ157). This project has been funded by the innovative research project of postgraduates of Southwest University for Nationalities ("Challenges and Policy Options for Population Aging in Xinjiang Production and Construction Corps" Project number: CX2018SZ157). the aging problem, aiming to provide Corps with relevant theoretical basis and practical evidence.

\section{The CURRENT SituAtion OF AgING OF XinJIANG PRODUCTION AND CONSTRUCTION CORPS}

\section{A. The Aging Status in Corps Has the Characteristics of Early Time and High Degree}

In the Corps, the number of elderly people aged over 60 reached 265,200 as early as 1982 , accounting for $12 \%$ of the total population of the Corps. In this period, the Corps had entered an aging society, earlier than the entire country and the Uygur Autonomous Region. In the meantime, on average, more than 10,000 people reached 60 years old each year since then, and the aging social process is constantly aggravating.

According to the "2010 Main Data communiqué of the 6th National Census and Corps Demographic Surveys of the Corps", the number of people over 65 years old is 293,500 , accounting for $11.3 \%$ of the total 1 . Compared with the previous census data, the proportion of the aging population in 2010 Census Data increases by $5.6 \%$. The aging speed of the area is also growing faster than that of other areas.

\section{B. The Demographic Structure in Corps Has Serious Age-} related Fault, with Obvious Aging Stage Characteristics

The organization of Corps is special, and is basically composed of the immigrant population. In 1954-1961, China vigorously advocated and organized many people to join the great construction of Corps. The initially established population of Corps is 174,400 people, and in 1974, it rapidly grew to $2,251,700$ people. During the 20 years development of the Corps, the population net increased by 2081700 [2]. However, the first and second generation settlers who came to the Corps in their early years are now

Statistical Bureau of Xinjiang Production and Construction Corp. 2011 Statistical Yearbook of Xinjiang Production and Construction Corp [Z]. Beijing, China Statistics Press. 2012

He Yuanchao, Yan Haiyan. Study on the Population Development of Corp in the New Period [C]. Theoretical Research Society Secretariat of Corp. excellent essays of 2010 Corp Population Theory Research Association. Internal information. 2010.31 
already old. At this stage, the population of Corps has entered to the situation where there is a large proportion of the aging population with the prominent aging phenomenon and grim situation and the stage characteristics is shown, making the Corps faces difficulties of having no successor, so that the economy is hard to develop and the aging population is not optimistic.

\section{The Challenges Posed By the AgING OF POPULATION IN XINJIANG PRODUCTION AND CONSTRUCTION CORPS}

\section{A. Challenges Brought by Aging of the Corps to Economic Development}

1) The Corps grows old before becoming rich, with large pressure in economic development: As a special kind of social organization, the Corps is located in a remote area with poor natural conditions and the establishment of the Corps started late. Many reasons have led to difficulties in economic development. The per capita income of Corps in the early years of establishment was below the average level in China and there was a large gap. Today, after 63 years of development, the per capita income of Corps has risen, but it is still at a low level in China. In recent years, the Corps has always served as a state-backed frontier area. However, relying merely on the continuous input of external forces but lacking internal drive can't completely solve the fundamental problems for backward economic development of Corps.

2) Aging seriously constrains private investment and restricts economic development: In general, elders in Corps are accustomed to actively save money before retirement for emergency relief so that they can allocate their own pension after retirement. After retirement, the income of the elderly is reduced, but medical expenses become larger, so the corresponding savings are reduced. The reduction of private investment directly affects the economic expansion production and seriously restricts the economic development of the Corps.

\section{B. The Negative Influence of Aging of the Corps on the Development of the Three Major Industries}

According to the distribution structure of employees in various industries in the Corps in "Table I", the population proportion of primary industry is the highest, which is basically above $45 \%$ in the past years. The Corps is obviously the area taking the primary industry as main industry [3]. From the table, it can be seen that from 1985 to 2010, the number of primary industries is decreasing. According to the law of economic development, the decrease in the population number of primary industry is a sign of social modernization. However, unlike other areas of China, Corps has a high demand for the working population relying

Wang Yongjing, Wu Xinping, et al. The contribution of Corp population changes to the economic development [C]. Theoretical Research Secretariat of Corps. Excellent essays of 2010 Corp Population Theory Research Association. Internal data, 2012: 11. on primary industry. The better economic development of Corps depends on the labor force, but now the decreasing labor force led to the shortage of labor in the primary industry, and the labor force of secondary industry is also reduced. Besides, it can be found that the population of the tertiary industry is on the rise. It is known that since the population engaged in this industry has risen and among them, the middle-aged population is majority, the age structure of employed workers caused by labor shortage is irrational. The economic development of the three industries under the aging of Corps has been severely hampered.

TABLE I. STRUCTURE OF SOCIAL WORKERS IN THE THREE MAJOR INDUSTRIES IN CORPS IN SELECTED YEARS (\%)

\begin{tabular}{clll}
\hline Year & $\begin{array}{c}\text { The Primary } \\
\text { Industry }\end{array}$ & $\begin{array}{c}\text { The Secondary } \\
\text { Industry }\end{array}$ & $\begin{array}{c}\text { The Tertiary } \\
\text { Industry }\end{array}$ \\
\hline 1985 & 56.2 & 28.4 & 15.4 \\
1995 & 47.2 & 29.6 & 23.2 \\
2005 & 49.0 & 19.5 & 31.5 \\
2010 & 45.8 & 19.8 & 34.4 \\
\hline
\end{tabular}

${ }^{\text {a. }}$ Data Source: 2011 Statistical Yearbook of Xinjiang Production and Construction Corps

\section{Challenges of Corps Population Aging to Society}

1) A serious lack of social labor: The adequate and lowcost labor force of Corps is the basis for economic development of it,and its labor-intensive modern agriculture has a very strong advantage internationally. By the end of 2010, the number of retired staff of the Corps rose to 514,524 , with a ratio of 0.9: 1 between the number of retired staff and those on duty of the Corps in that year. Aging of Corps, the low birth rate and population movements contributed to the serious supply of labor force Insufficient [4]. For the Corps, the population aging trend will weaken the advantage of modern agriculture of Corps.

2) It is not conducive to maintaining the stability of the border: Firstly, it affects the stability and unity of the border of Corps. These areas are unable to retain the talent in the region, and it is also difficult to introduce talents from other regions. Under such circumstances, the Corps can only rely on the development of the second generation of soldiers. However, most of people in this group are old. The Corps that loses the depending strength adversely affects the unity and stability of the border areas. At the same time, the low birth rate and the loss of large numbers of population have weakened the region's influence, which have also hit the construction of the team that maintains the stability of the frontier.

\section{Challenges of Corps Aging to the Old-age Security System}

Corps population aging makes the pension security system face great challenges. As the number of aging in the society increases, this group's demand for pension, annuity and medical security is increasing. As a special social

\footnotetext{
$4 \quad$ Statistical Bureau of Xinjiang Production and Construction Corp. 2011 Statistical Yearbook of Xinjiang Production and Construction Corp [Z]. Beijing, China Statistics Press. 2012.
} 
organization, XPCC did not promptly improve its old-age security system in the initial stage of its establishment. Nowadays, due to the early policy and other reasons, the problem of pay-as-you-go pension system is intensified facing the acceleration of the aging process. As can be seen from "Table II", in the nine years from 2002 to 2010, the pension expenses increased from 3,177.8 million yuan in 2002 to 91.79 million yuan [5] in 2010, an increase of nearly twice as much, so Corps finance faces enormous pressure for pension.

TABLE II. PENSION EXPENSES OF CORPS IN SOME YEARS UNIT: TEN THOUSAND YUAN

\begin{tabular}{|l|l|}
\hline \multicolumn{1}{|c|}{ Year } & Pension expenses \\
\hline 2002 & 315780 \\
\hline 2003 & 325772 \\
\hline 2004 & 350121 \\
\hline 2005 & 370563 \\
\hline 2006 & 431658 \\
\hline 2007 & 507957 \\
\hline 2008 & 604009 \\
\hline 2009 & 701686 \\
\hline 2010 & 917950 \\
\hline
\end{tabular}

b. Data Source: 2011 Statistical Yearbook of Xinjiang Production and Construction Corps

\section{E. Challenges of Corps Population Aging to the Pension Service System}

The pension service of Corps is inadequate and contradiction between supply and demand of pension services is prominent. For a long time, the Corps has strictly followed the family planning policy, leading to the weakening of the family aging care function and further aggravating the aging problem of Corps. Corps has a high proportion of the aging population, reaching $18 \%$ of the total population. Since the 12th Five-Year Plan, the units at all levels of Xinjiang Corps have invested 210 million yuan in building community service centers for the elderly and built 84 service centers. In 2013, the division at the level 3 set up 83 pension service agencies, providing 4806 beds [6]. This year, the elderly population over 60 years old of Corps is 460,000 , so the potential demand for pension institutions is very large, and existing pension service institutions of Corps is difficult to meet the pension needs.

\section{The POLICY CHOICES OF XinJiAng PRODUCTION AND CONSTRUCTION CORPS FACING POPULATION AGING}

\section{A. To Strengthen and Improve the Pension System of Corps}

In recent years, due to the increase of the elderly population and the acceleration and deepening of the aging process, the financial pressure of pension insurance in Corps has been increasing and the state and the society are facing huge burden on the elderly caring. In view of this, the pension funds can be assumed jointly by the state, the

Statistical Bureau of Xinjiang Production and Construction Corp. 2011 Statistical Yearbook of Xinjiang Production and Construction Corp [Z]. Beijing, China Statistics Press. 2012.

Shen Xiaomei, Li Hui. Analysis on the Aging Problem of Corp Population [J]. Journal of Shihezi University (Philosophy and Social Science), 2013, (6): 71-47. collective and the individuals. The old-age security departments of Corps should reasonably formulate the pension insurance system fully combining with the actual situation, and reasonably distribute the proportion of pensions paid by groups and businesses. At the same time, the scope of the collection of pension insurance will be extended to self-employment venture, private enterprise and joint-equity enterprise.

\section{B. To Use the Policy to Optimize the Population Structure and Increase the Proportion of Working Population}

1) To adjust childbearing policy: The people of Corps always strictly abide by Chinese family planning policy, so the population growth in this area has always been "low birth, low death and low growth", and so does the southern Xinjiang Corps. We should properly adjust the family planning policy of the Corps to deal with the aging population. On the one hand, we can strengthen the education of prenatal and postnatal care to all ethnic groups in the southern border of the Corps. On the other hand, they should be encouraged to respond to the second child policy and be given special maternity benefits to increase the population, balance the unequal distribution of population in the area of the Corps in North and South Xinjiang and increase the proportion of the working population in the Corps.

2) to implement the tilt policy to attract and retain young talents

Today, aging problem of Corps needs to be fundamentally resolved, and attracting and retaining talent is the crux of the issue, which requires the support and assistance of the corresponding national policy. We need to actively implement the "double-five-thousand" plan. First is to enroll 5,000 rural labor force aged 18-25 each year, and second is to allow 5,000 outstanding graduates who have not yet obtained employment and veterans to settle in the secondary and tertiary industries and business of Corps. For the children of staff in round field who are willing to stay, we help to arrange suitable jobs. We should reform the mechanism of the work units in the round field and inspect the young and middle-aged cadres among whom outstanding cadres can be appointed to the round field. We need to actively build round field, lead the social and economic development of the round field and encourage settlement, and give preferential policies so as to retain population and talents, solve the problem of labor shortage, and increase the natural growth rate of the Corps' population and the proportion of working population.

\section{Build the "Productive Aging" of Corps}

China has the basic conditions for the implementation of productive aging. However, it has not drawn the corresponding attention all along. We should learn from the Western countries to encourage older workers to re-employ when actively formulate various incentive policies to maintain the enthusiasm and vitality of older workers on work and life. Corps should speed up the construction of "productive aging" and fundamentally solve the economic 
and social problems brought by the increasingly prominent aging of Corps. The "productive aging" policy is a direct solution to the problem of aging, which not only achieves theoretical innovation but also reduces the financial pressure of the Corps and at the same time increases the economic income of the Corps.

We can vigorously develop the cause of the elderly to encourage older people to re-employ. It is proposed that Corps government can broaden the employment content of the elderly in relevant policies, and the flexible employment and some social compulsory service for elderly can be included. For example, they can continue to create value for the society to give full play to the "afterheat" of the elderly human resources through voluntary contributions, selfemployment and rehiring. According to the survey data, many energetic and capable seniors are very willing to continue to contribute to the society. When Corps expands the pension service industry, the number of jobs will increase correspondingly, and some energetic elderly people can contribute to the Corps pension construction as workers or voluntary service providers.

\section{To Speed up Corps Pension Service System}

However, due to the deep degree and rapid process of aging population of the Corps, prevalence rate is increasing with age, which is unmanageable for the Corps' current medical security system. We need to improve the medical security system in these areas: to raise the medical standards of the Corps by introducing the same medical technology as the city; to increase the coverage of medical insurance so that the non-staff population can enjoy the medical security system; to increase the level of overall coordination and diversify the way of financing; to improve the medical management system and promote the efficient operation of medical insurance.

We can establish and improve Corps pension service system, build the aging industry, optimize the consumption structure and promote the economy. First of all, it is necessary to raise the proportion of pension infrastructure in the planning of the Corps and establish public welfare activities and service agencies for the elderly of Corps. We can also coordinate with the market to encourage the establishment of various types of private pension services and industries. On the one hand, when the Corps aging industry is improved, many new jobs are also created, which can bring in both young labor force and elder people who have energy.

Corps should support and encourage the innovative pension industry and provide policy support. We can build industries targeted at the elderly in the Corps, the products and services provided to the elderly should be compatible with the physiological and psychological needs of the elders in Corps. At present, the development of Corps aging industry lags behind and cannot meet the needs of the elderly.

\section{CONCLUSION}

One of the problems that have troubled the development of Xinjiang Production and Construction Corps in all aspects of its economy and society nowadays is the aging population of Corps. It is a complicated and systematic project with high difficulty, wide scope, heavy tasks and tight time to establish and improve relevant policies to ease the problem of aging in the social process Corps with fast speed and deep degree aging in Corps. In response to the aging of Corps, we need to make a sound old-age security system in terms of economic development, industrial development, old-age security and old-age care service system, formulate incentives for the introduction of qualified personnel, build productive aging to develop the cause for aging, and accelerate the improvement of the aged care service system so as to effectively solve the problem of aging and promote the fast and sound development of the economy and society of Corps.

\section{REFERENCES}

[1] Statistics Bureau of Xinjiang Production and Construction Corps 2011 Statistical Yearbook of Xinjiang Production and Construction Corps [Z]. Beijing, China Statistics Press. 2012.

[2] He Yuanchao, Yan Haiyan. Study on the Population Development of Corps in the New Period [C]. Theoretical Research Society Secretariat of Corps. excellent essays of 2010 Corps Population Theory Research Association. Internal information. 2010.31

[3] Statistics Bureau of Xinjiang Production and Construction Corps 2015 Statistical Yearbook of Xinjiang Production and Construction Corps [Z]. Beijing, China Statistics Press, 2015.

[4] Wang Yongjing, Wu Xinping, et al. The contribution of Corps population changes to the economic development [C]. Theoretical Research Secretariat of Corps. excellent essays of 2010 Corps Population Theory Research Association. internal data, 2012: 11.

[5] Shen Xiaomei, Li Hui. Analysis on the Aging Problem of Corps Population [J]. Journal of Shihezi University (Philosophy and Social Science), 2013, (6): 71-47.

[6] Li Shuang, Xu Yuanbo, Ding Yaqiu. Study on the problem of Elderly Security in Xinjiang Corps under the Analysis on Prediction on the Trend of Population Aging [J]. Journal of the Party School, 2015 (06) 16-21.

[7] Liu Xiaofei. Influence of Corps Aging on Reclaiming Wasteland [J] Manager' Journal, 2016 (18): 147.

[8] Cheng Yuanshun. Study on Public Policy of Population Aging [D]. Hebei University, 2013. 